\title{
Panorama da energia eólica sob a perspectiva dos impactos ambientais no Brasil
}

\section{Cristhian Carla Bueno de Albuquerque ${ }^{1}$, Lucas Rodrigues Maciel $^{2}$, Silvana Nakamori ${ }^{3}$,* Talila Auler ${ }^{4}$ e Anderson Catapan $^{4}$}

${ }^{1}$ Tribunal de Contas do Estado do Paraná. Praça Nossa Senhora da Salete, S/№. Centro Cívico. Curitiba-PR, Brasil (CEP 80530-910).

${ }^{2}$ Secretaria de Planejamento e Coordenação Geral do Estado do Paraná. Palácio das Araucárias. Rua Jacy Loureiro de Campos, s/n, 4oandar. Centro Cívico. Curitiba-PR, Brasil (CEP 80530-140).

${ }^{3}$ Universidade Federal do Paraná. Centro Politécnico. Avenida Coronel Francisco Heráclito dos Santos, 100. Edifício de Administração, 2o andar. Jardim das Américas. Curitiba-PR, Brasil (CEP 81531-980). *E-mail: silvananakamori@gmail.com.

${ }^{4}$ Universidade Tecnológica Federal do Paraná. Programa de Pós-Graduação em Planejamento e Governança. Avenida Sete de Setembro, 3165. Curitiba-PR, Brasil (CEP 80230-901).

Resumo. A presente pesquisa objetiva traçar um panorama da energia eólica sob a perspectiva dos impactos ambientais no Brasil. Para tanto, se valeu de uma revisão sistemática, a partir de um processo estruturado de busca de trabalhos científicos junto ao Portal de Periódicos da Capes. A revisão sistemática permitiu aferir que, dentre os principais impactos abordados, estão os de natureza sonora, visual, de restrição na utilização do solo e na utilização dos terrenos, de acidentes com aves e de radiação eletromagnética. No entanto, foi possível identificar que há convergência de quase a totalidade das pesquisas no sentido de que as potencialidades e os impactos positivos da fonte eólica ainda a tornam um meio de produção sustentável e de baixo impacto, em que pese as externalidades negativas. 0 presente estudo permite aferir as lacunas existentes quando se fala em pesquisa de impacto ambiental da energia eólica no Brasil, bem como das formas de mitigação destes impactos.

Palavras-chave: Energia eólica; Impactos ambientais; Sustentabilidade; revisão sistemática.

Abstract. Wind energy overview from the perspective of environmental impacts in Brazil. This research aims to draw an overview of wind energy from the perspective of environmental impacts in Brazil. To this end, it made use of a systematic review, based on a structured process of searching for scientific work at the Capes Journal Portal. The systematic review allowed us to
Recebido

$10 / 09 / 2019$

Aceito

$30 / 11 / 2019$

Disponível on line

$01 / 12 / 2019$

Publicado

31/12/2019

Acesso aberto

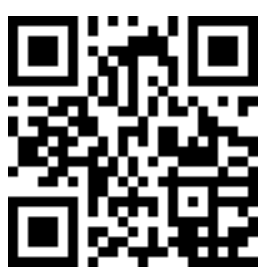

ORCID

(1) 0000-0003-0897-892X Cristhian Carla Bueno de Albuquerque 
verify that, among the main impacts addressed, are those of sound, visual nature, restriction of land use and land use, accidents with birds and electromagnetic radiation. However, it was possible to identify that almost all research converges in the sense that the potentialities and positive impacts of the wind source still make it a sustainable and low impact means of production, despite the negative externalities. This study allows us to gauge the gaps that exist when it comes to research on the environmental impact of wind energy in Brazil, as well as on ways to mitigate these impacts.

Keywords: Wind energy; Environmental impacts; Sustainability; Systematic review.

\section{Introdução}

Decorrente da maior percepção e atenção destinada aos problemas ambientais relativos à geração de energia, nos últimos anos foi incentivado o desenvolvimento de fontes alternativas denominadas energias renováveis, orientadas pelo desenvolvimento sustentável e pela busca em atender a demanda energética da sociedade (Campêlo, 2016).

Uma alternativa para diminuir problemas ambientais e relativos ao aquecimento global, bem como atender à crescente demanda por energia é utilizar energias renováveis, tais como energia da biomassa, solar e a eólica (Ribeiro et al., 2012)

Além dos problemas ambientais, outro elemento que fomenta a busca por fontes renováveis é o custo elevado da geração por fontes tradicionalmente utilizadas, sendo este fator um dos responsáveis pelo incentivo da produção de energia por fonte eólica em diversos países (Loureiro et al., 2015).

A energia eólica produz menos degradação ao meio ambiente, durante a sua produção não são emitidos os gases do efeito estufa, a exemplo do gás carbônico ( $\mathrm{CO} 2)$, metano $\left(\mathrm{CH}_{4}\right)$, óxido de nitrogênio $\left(\mathrm{N}_{2} \mathrm{O}\right)$, hidrofluorcarbonos (HFCs), perfluorcarbonos (PFCs) e hexafluoreto de enxofre $\left(\mathrm{SF}_{6}\right)$ (Medeiros et al., 2009; Ribeiro et al., 2012; Lima e Oliveira, 2015).
D) $0000-0002-9346-4669$

Lucas Rodrigues

Maciel

(1) 0000-0002-0749-1637

Silvana Nakamori

() 0000-0003-0687-1221

Talila Auler

(ㄱ) 0000-0003-1883-2414

Anderson Catapan
A indústria eólica atualmente abrange mais de 80 países, sendo a China, a Índia e a América Latina mercados em crescimento (Gorayeb e Brannstrom, 2016). Nos últimos anos, o Brasil tem ampliado o investimento em projetos de geração de energia por meio da fonte eólica (Oliveira et al., 2018), o que vem sendo fomentado por meio de incentivos e programas federais (Nascimento et al., 2012; Loureiro et al., 2015).

De acordo com os dados Associação Brasileira de Energia Eólica (ABE Eólica, 2009), o país apresenta mais de 7 mil aerogeradores, em 601 parques eólicos, em 12 estados. Atualmente, a geração de energia eólica responde pela segunda fonte mais utilizada no Brasil para a produção de energia elétrica, tendo $15 \mathrm{GW}$ de capacidade instalada.

Entretanto, a indústria eólica em torno da geração de energia, embora reúna em sua grande maioria impactos socioambientais positivos, pode também ocasionar impactos ambientais que devem ser analisados e mitigados, dentre os quais os sonoros e os visuais (Loureiro et al., 2015).

Além disso, observa-se que durante a fase de implantação dos parques eólicos são gerados impactos ambientais decorrentes da atividade de construção civil que são incorporados pelo ambiente (Oliveira et al., 2018).

Assim, considerando a contextualização apresentada, a questão de pesquisa deste artigo é quais são os 
principais fatores ambientais negligenciados na produção de energia eólica no Brasil? 0 presente estudo consiste em identificar por meio de uma revisão sistemática de literatura os principais fatores ambientais atrelados a essa fonte de energia renovável.

Esta problemática demanda resposta sob a perspectiva da mitigação dos impactos ambientais gerados a partir de fontes eólicas ou na consolidação da sustentabilidade desta matriz energética. Para tanto, foram reunidos e analisados artigos científicos sobre o tema, conforme restará detalhado na seção metodológica, a partir dos quais foram extraídos os resultados e conclusões desta pesquisa.

A contribuição teórica da pesquisa consiste no agrupamento e na abordagem dos impactos ambientais ocasionados pela geração da energia eólica; e, a contribuição prática reside na possibilidade do aperfeiçoamento dos dispositivos mitigadores dos impactos ambientais gerados na produção deste tipo específico de energia renovável.

Este recorte limita-se ao âmbito brasileiro devido ao rápido avanço da indústria eólica no país nos últimos anos, tornando-se a segunda fonte mais utilizada na geração de energia de acordo com ABE Eólica.

\section{Método de pesquisa}

\section{Caracterização da pesquisa}

No que tange à natureza do objetivo, seguindo orientação de Vergara (2013) a metodologia adotada se caracteriza como exploratória, uma vez que constitui um primeiro levantamento sobre o tema; e descritiva, pois exibe, de forma descritiva, os procedimentos que foram seguidos e os resultados encontrados. Em relação à natureza da pesquisa, ela é classificada, conforme taxionomia de Gil (2010) como levantamento bibliográfico, buscando uma reflexão sobre o problema a partir da utilização de materiais já publicados (livros, periódicos, teses, etc.).
Concernente à coleta de dados, o presente estudo se baseia em pesquisa de dados secundários, ou seja, artigos científicos disponibilizados gratuitamente nas bases de dados indexadas ao Portal da Capes.

Quanto à abordagem do problema, a pesquisa é qualitativa, devido à estrutura de coleta de dados secundários e sua análise em relação à permanência no portfólio bibliográfico, sem adentrar na análise quantitativa, no que concerne à análise bibliométrica do conjunto de artigos obtidos (Soares et al., 2016).

Com relação aos resultados obtidos, a pesquisa se classifica como aplicada (Vergara, 2013), pois são coletados dados a partir de um procedimento estruturado, que, posteriormente, são analisados seguindo igualmente uma metodologia estruturada.

No que diz respeito à população e amostra, são considerados como população alvo do trabalho toda publicação científica em periódico que compreenda o tema energia eólica sob a perspectiva dos impactos ambientais gerados por essa fonte no Brasil, disponíveis no Portal da Capes.

A amostra utilizada teve por referência os artigos selecionados nas bases de dados reunidas no Portal da Capes Brasil com maior aderência ao tema de pesquisa e maior quantidade de publicações na área. Dessa forma, o procedimento de seleção do portfólio bibliográfico foi aplicado no presente estudo.

\section{Delineamento metodológico}

A pesquisa teve início a partir da revisão sistemática da literatura, tendo por objetivo abordar a energia renovável a partir da fonte eólica no Brasil com enfoque nos possíveis impactos ambientais. A revisão sistemática da literatura por meio de um processo estruturado de busca possibilita identificar lacunas da literatura bibliográfica, e a extração de uma parte 
específica e relevante de publicações consoantes aos objetivos propostos para pesquisa, procurando suprir eventuais limitações dos estudos analisados (Fernandes, 2017).

A escolha do Portal da Capes se deu em razão dele possuir uma biblioteca virtual que reúne e disponibiliza uma ampla produção científica nacional e internacional, contando com um acervo de mais de 45 mil periódicos com textos completos, 130 bases referenciais, 12 bases dedicadas a patentes, além de enciclopédias, livros, normas técnicas e obras de referência (Capes, 2019), bem como, pelo recorte da pesquisa no âmbito do Brasil.

A seleção do portal Portal da Capes foi feita buscando incluir periódicos internacionais e nacionais, de acesso aberto, por meio das palavraschaves selecionadas, as quais foram utilizadas nos mecanismos de busca de artigos científicos, isoladamente e combinadas, uma vez que o tema contempla mais de uma linha de pesquisa.

Com o intuito de atender aos objetivos do presente artigo, atendo-se ao tema aqui proposto, as buscas foram realizadas a partir de combinações das palavras-chave "energia eólica no Brasil", "conflitos ambientais", "impactos ambientais", "ambiental", "sustentabilidade" e "energia eólica".

Para fins de verificar se as palavras-chave selecionadas estavam adequadas ao tema de pesquisa realizouse a leitura dinâmica dos títulos dos artigos entre aqueles obtidos na pesquisa, cuja leitura permitiu identificar que havia outras palavras-chaves que poderiam ser utilizadas, a exemplo da "sustentabilidade", as quais foram incorporados na busca pelos artigos científicos.

Sinteticamente, os passos seguidos inicialmente são mostrados na Figura 1.

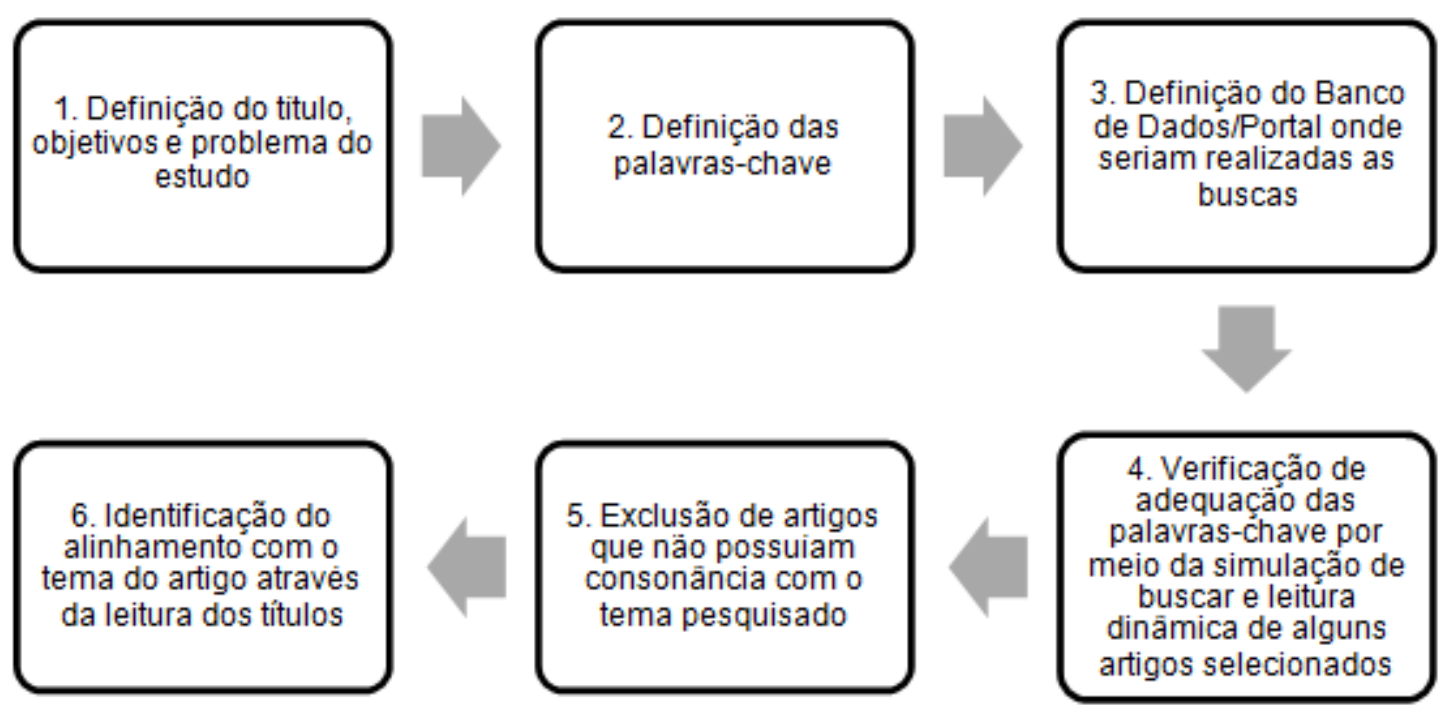

Figura 1. Etapas da revisão.

Seguindo as especificações da metodologia de revisão sistemática (Duarte et al., 2017) foi realizada a classificação dos artigos quanto ao tipo de pesquisa: artigos originais e de revisão, sendo excluídas respostas a debates e resenhas de livros; e os termos usados para a busca foram em português, com os termos energia eólica no Brasil e conflitos ambientais; energia eólica no Brasil e impactos ambientais; energia eólica no Brasil e ambiental; energia 
eólica no Brasil e sustentabilidade; energia eólica e sustentabilidade; energia eólica e ambiental; todos os termos entre aspas duplas.

Após a pré-seleção dos artigos pelos seus títulos, realizou-se uma leitura do resumo, e foram eliminados os artigos relacionados à energia eólica no Brasil, mas que não abordavam os impactos ambientais e os aspectos de sustentabilidade, foco do presente estudo, bem como, os artigos repetidos.

Não foi estipulado um período de publicações, uma vez que o acervo referente ao tema se mostrou exíguo, assim, foram considerados todos os artigos disponíveis até julho de 2019, e a opção por delimitá-lo ao Brasil decorre da delimitação do tema e do objetivo do estudo que visa traçar um panorama da energia eólica sob a perspectiva dos impactos ambientais no Brasil.

\section{Coleta de dados}

A busca dos termos em português resultou em 400 trabalhos indexados no Portal da Capes, cuja seleção foi feita com base na análise primeiramente dos títulos, a fim de verificar se os critérios de inclusão de artigos para fins desta pesquisa eram atendidos. Cada artigo selecionado foi analisado e classificado quanto ao tema abordado, enfoque e objetivo de pesquisa, sendo que do total 23 tinham correlação com o objeto de estudo.

A definição dos enfoques de pesquisa emergiu da leitura dos textos e houve também o emprego do método de checagem, no qual três pessoas realizaram o mesmo procedimento de busca, seleção e análise dos artigos, com posterior comparação e discussão dos resultados (Tabela 1 ).

Tabela 1. Seleção inicial dos artigos.

\begin{tabular}{|l|c|c|c|}
\hline Parâmetro de pesquisa & $\begin{array}{c}\text { Portal de } \\
\text { periódicos } \\
\text { CAPES/MEC }\end{array}$ & $\begin{array}{c}\text { Artigos } \\
\text { repetidos }\end{array}$ & $\begin{array}{c}\text { Artigos } \\
\text { excluídos }\end{array}$ \\
\hline "energia eólica no Brasil" & 13 & - & 2 \\
\hline $\begin{array}{l}\text { "energia eólica no Brasil" and "conflitos } \\
\text { ambientais" }\end{array}$ & 1 & 1 & - \\
\hline $\begin{array}{l}\text { "energia eólica no Brasil" and "impactos } \\
\text { ambientais" }\end{array}$ & 2 & 1 & 1 \\
\hline "energia eólica no Brasil" and "ambiental" & 4 & 2 & 2 \\
\hline "energia eólica no Brasil" and "sustentabilidade" & 6 & 5 & 1 \\
\hline "energia eólica" and "sustentabilidade" & 85 & 5 & 70 \\
\hline "energia eólica" and "ambiental" & 289 & 4 & 283 \\
\hline
\end{tabular}

As exclusões ocorreram em virtude de os artigos possuírem abordagem a estudos de casos internacionais, e seus títulos serem incompatíveis com a proposta de pesquisa deste artigo, totalizando o montante de 359 (trezentas e cinquenta e nove) exclusões.

Os artigos repetidos totalizaram 18 (dezoito), restando 23 (vinte e três) artigos que a princípio se relacionavam com o problema e objetivo do presente estudo. A partir de então, foi realizada a triagem dos resultados obtidos com a leitura dos 23 (vinte e três) artigos.

As principais divergências encontradas foram discutidas entre os autores e se referiram à manutenção ou remoção dos artigos que possuíam como enfoque os impactos sociais. Assim, ao final das análises, 12 artigos foram removidos (Tabela 2). 
Tabela 2. Artigos removidos após verificação de inadequação temática.

\begin{tabular}{|c|c|}
\hline Título do artigo & Motivo da exclusão \\
\hline $\begin{array}{l}\text { Metodologia simplificada para avaliação do potencial de } \\
\text { energia eólica em centros urbanos }\end{array}$ & $\begin{array}{l}\text { Dados meteorológicos; Análise do } \\
\text { potencial de energia eólica. }\end{array}$ \\
\hline $\begin{array}{l}\text { Como vento a favor: expansão na capacidade de geração, } \\
\text { investimentos de fornecedores de equipamentos e redução de } \\
\text { preço começam a tornar a energia eólica competitiva no Brasil. } \\
\text { (BRASIL: energia) }\end{array}$ & $\begin{array}{l}\text { Investimentos; equipamentos e } \\
\text { redução de preço; } \\
\text { competitividade, viabilidade } \\
\text { econômica. }\end{array}$ \\
\hline $\begin{array}{l}\text { Energia eólica, geração de empregos e desenvolvimento } \\
\text { sustentável }\end{array}$ & $\begin{array}{c}\text { Geração de empregos e enfoque } \\
\text { social. }\end{array}$ \\
\hline $\begin{array}{l}\text { Wind-energy Development Causes Social Impacts in Coastal } \\
\text { Ceará state, Brazil: The Case of the Xavier Community }\end{array}$ & Enfoque apenas social. \\
\hline Análise regional da energia eólica no Brasil & $\begin{array}{l}\text { Desenvolvimento da energia } \\
\text { eólica no Brasil. }\end{array}$ \\
\hline $\begin{array}{l}\text { Avaliação da energia eólica no Brasil utilizando a análise SWOT } \\
\text { e PESTEL. }\end{array}$ & Enfoque econômico. \\
\hline $\begin{array}{l}\text { Estados que vivem de vento: um leilão de energia eólica em } \\
\text { novembro deve impulsionar o setor, ainda insignificante no } \\
\text { país, mas que tem tudo para atrair bilhões de reais e ajudar a } \\
\text { desenvolver a economia do Nordeste. }\end{array}$ & $\begin{array}{l}\text { Leilão de energia eólica, } \\
\text { potencialidades da energia eólica } \\
\text { no Nordeste brasileiro. }\end{array}$ \\
\hline $\begin{array}{l}\text { "Do que você lembra quando pensa em energia do vento?" Um } \\
\text { estudo sobre o conhecimento da energia eólica }\end{array}$ & $\begin{array}{l}\text { Conhecimento sobre energia } \\
\text { eólica de } 191 \text { estudantes, enfoque } \\
\text { geral. }\end{array}$ \\
\hline $\begin{array}{l}\text { Energia Eólica: Um Estudo sobre a Percepção Ambiental no } \\
\text { Município de Currais Novos-RN }\end{array}$ & Enfoque social. \\
\hline $\begin{array}{l}\text { O uso e a importância dos indicadores de sustentabilidade nas } \\
\text { organizações--estudos de casos em empresas de energia } \\
\text { elétrica. }\end{array}$ & $\begin{array}{l}\text { Análises da importância de } \\
\text { indicadores de sustentabilidade }\end{array}$ \\
\hline $\begin{array}{l}\text { Manpoe Barmaseinl to Tecnologico de Patentes em Energia } \\
\text { Eólica/Technology Mapping of Wind Energy Patents in Brazil. } \\
\text { (Report) }\end{array}$ & $\begin{array}{l}\text { Desenvolvimento da tecnologia } \\
\text { eólica, patentes, atividades } \\
\text { inovativas. }\end{array}$ \\
\hline Geração de energia eólica no Brasil: um investimento viável? & Enfoque econômico. \\
\hline
\end{tabular}

Por fim, dos 23 artigos encontrados, 11 foram mantidos na pesquisa e formam a base da revisão sistemática, em razão da pertinência temática de seu conteúdo aos objetivos aqui propostos (Tabela 3 ).

Foram selecionados apenas os artigos revisados por pares, excluindo-se já na seleção prévia as produções acadêmicas sobre o panorama da energia eólica sob a perspectiva dos conflitos ambientais no Brasil relativas a teses e dissertações, capítulos de livros, trabalhos publicados em anais de congressos científicos e em periódicos não indexados às bases consultadas. 
Tabela 3. Seleção final dos artigos para revisão sistemática.

\begin{tabular}{|c|c|}
\hline Título do artigo & Pertinência temática \\
\hline $\begin{array}{l}\text { Implantação de energia eólica e estimativa das perdas } \\
\text { ambientais em um setor do litoral oeste do Ceará, Brasil. }\end{array}$ & Possui enfoque ambiental. \\
\hline $\begin{array}{l}\text { Energias Renováveis e Sustentabilidade: um olhar geográfico } \\
\text { para o parque eólico de Marcolândia, estado do Piauí, Brasil. }\end{array}$ & Possui enfoque ambiental. \\
\hline $\begin{array}{l}\text { Projeto de Mecanismo de Desenvolvimento Limpo: Um Estudo } \\
\text { de Caso na Empresa de Energia Eólica do Estado do Piauí. }\end{array}$ & $\begin{array}{l}\text { Enfoque socioambiental, } \\
\text { sustentabilidade local. }\end{array}$ \\
\hline $\begin{array}{l}\text { Energia Eólica no Quintal da Nossa Casa?! Percepção Ambiental } \\
\text { dos Impactos Socioambientais na Instalação e Operação de uma } \\
\text { Usina na Comunidade de Sítio do Cumbe em Aracati. }\end{array}$ & $\begin{array}{l}\text { Enfoque socioambiental e } \\
\text { sustentabilidade }\end{array}$ \\
\hline $\begin{array}{l}\text { Poluição Sonora: um estudo de caso do parque eólico Asa } \\
\text { Branca II, localizado no Município de Parazinho-RN. }\end{array}$ & Enfoque ambiental. \\
\hline $\begin{array}{l}\text { Tendências do cenário energético brasileiro: a energia de fonte } \\
\text { eólica e o "olhar" dos atingidos. }\end{array}$ & Enfoque socioambiental. \\
\hline $\begin{array}{l}\text { Inovação e sustentabilidade na produção de energia: o caso do } \\
\text { sistema setorial de energia eólica no Brasil. }\end{array}$ & Enfoque ambiental. \\
\hline $\begin{array}{l}\text { Energia eólica: por uma revisão das bases energéticas e } \\
\text { incentivo a economia de baixo carbono. }\end{array}$ & $\begin{array}{l}\text { Desenvolvimento sustentável, } \\
\text { enfoque ambiental. }\end{array}$ \\
\hline $\begin{array}{l}\text { Caminhos para uma gestão participativa dos recursos } \\
\text { energéticos de matriz renovável (parques eólicos) no nordeste } \\
\text { do Brasil. }\end{array}$ & Enfoque ambiental. \\
\hline $\begin{array}{l}0 \text { mercado brasileiro da energia eólica, impactos sociais e } \\
\text { ambientais. }\end{array}$ & Enfoque social e ambiental. \\
\hline $\begin{array}{l}\text { Sustentabilidade municipal e empreendimentos eólicos: uma } \\
\text { análise comparativa de municípios com investimentos na } \\
\text { geração de energia eólica no Brasil. }\end{array}$ & Enfoque ambiental. \\
\hline
\end{tabular}

Os artigos selecionados oferecem uma perspectiva do que tem sido pesquisado em relação aos conflitos ambientais e sustentabilidade no que tange a energia eólica no Brasil. E, abrangendo apenas trabalhos publicados em periódicos científicos indexados, ela sintetiza a produção acadêmica geralmente considerada como a mais relevante.

\section{Resultados}

A implementação de parques eólicos no Brasil iniciou-se na década de 1990, principalmente nas Regiões Norte e Nordeste em face das suas características climáticas e da acentuada carência de abastecimento elétrico em diversas áreas daquelas regiões (Pinto et al, 2017).

Por esta razão o acervo de pesquisas científicas existentes no Brasil sobre esta temática, em sua grande maioria, reflete levantamentos e estudos de casos realizados nas Regiões Norte e Nordeste brasileiras.

Neste contexto, o levantamento realizado no presente estudo sobre o panorama da energia eólica no Brasil, evidenciou 11 (onze) trabalhos com enfoque nos impactos ambientais, realizados em sua maior parte nos Estados do Ceará e Piauí (Tabela 4).

Assim, observa-se que ao analisar os impactos ambientais gerados pela energia eólica, a principal questão discutida pelos autores em suas pesquisas científicas refere-se à diminuição de emissões de gases de efeito estufa para produção de energia, os quais são uníssonos em reconhecer esta fonte renovável como de baixo impacto ambiental, afirmando inclusive que ela é a melhor maneira de agregar valor e obter rendimentos (Campêlo, 2016; Loureiro et al., 2015; Pinto et al, 2017). 
Tabela 4. Artigos que tratam dos impactos ambientais ocasionados pela geração de energia eólica.

\begin{tabular}{|c|c|c|c|}
\hline Título do artigo & $\begin{array}{c}\text { Impacto ambientais } \\
\text { gerados }\end{array}$ & Revista/ISSN & $\begin{array}{l}\text { Qualis } \\
\text { /JCR/SJR }\end{array}$ \\
\hline $\begin{array}{l}\text { 1. Implantação de energia } \\
\text { eólica e estimativa das } \\
\text { perdas ambientais em um } \\
\text { setor do litoral oeste do } \\
\text { Ceará, Brasil. }\end{array}$ & Sonoros e visuais & $\begin{array}{c}\text { Geosaberes: Revista de } \\
\text { Estudos } \\
\text { Geoeducacionais / } \\
2178-0463\end{array}$ & A1/- \\
\hline $\begin{array}{l}\text { 2. Energias Renováveis e } \\
\text { Sustentabilidade: um olhar } \\
\text { geográfico para o parque } \\
\text { eólico de Marcolândia, Piauí, } \\
\text { Brasil. }\end{array}$ & Visuais & $\begin{array}{c}\text { REGNE: Revista de } \\
\text { Geociências do } \\
\text { Nordeste / 2447-3359 }\end{array}$ & B5 / - \\
\hline $\begin{array}{l}\text { 3. Projeto de Mecanismo de } \\
\text { Desenvolvimento Limpo: } \\
\text { um estudo de caso na } \\
\text { empresa de energia eólica } \\
\text { do Estado do Piauí }\end{array}$ & Sonoros e visuais & $\begin{array}{c}\text { REUNIR: Revista de } \\
\text { Administração, Ciências } \\
\text { Contábeis e } \\
\text { sustentabilidade / } \\
\text { 2237-3667 }\end{array}$ & A4 / - \\
\hline $\begin{array}{l}\text { 4. Energia Eólica no quintal } \\
\text { de nossa casa? Percepção } \\
\text { ambiental dos impactos } \\
\text { socioambientais } \\
\text { instalação e operação de } \\
\text { uma usina na comunidade } \\
\text { de Sítio do Cumbe em } \\
\text { Aracati }\end{array}$ & $\begin{array}{c}\text { Restrição de } \\
\text { utilização do solo nas } \\
\text { proximidades } \\
\text { /utilização do terreno }\end{array}$ & $\begin{array}{l}\text { Revista de Gestão } \\
\text { Ambiental e } \\
\text { Sustentabilidade / } \\
2316-9834\end{array}$ & B3 / - \\
\hline $\begin{array}{l}\text { 5. Poluição sonora: um } \\
\text { estudo de caso do parque } \\
\text { eólico Asa Branca II, } \\
\text { localizado no Município de } \\
\text { Parazinho-RN }\end{array}$ & Sonoros & $\begin{array}{c}\text { Boletim de Geografia / } \\
\text { 2176-4786 }\end{array}$ & A3 / - \\
\hline $\begin{array}{l}\text { 6. Tendências do cenário } \\
\text { energético brasileiro: a } \\
\text { energia de fonte eólica e o } \\
\text { "olhar" dos atingidos }\end{array}$ & Social & $\begin{array}{c}\text { Revista Ciência e } \\
\text { Natura / 2179-460X }\end{array}$ & A3 / - \\
\hline $\begin{array}{lr}7 . & \text { Inovação } \\
\text { sustentabilidade } & \text { na } \\
\text { produção de energia: o caso } \\
\text { do sistema setorial de } \\
\text { energia eólica no Brasil }\end{array}$ & $\begin{array}{c}\text { Sonoros, visuais, } \\
\text { acidentes com aves e } \\
\text { radiação } \\
\text { eletromagnética }\end{array}$ & $\begin{array}{c}\text { Cadernos EBAPE, BR / } \\
2178-0463\end{array}$ & B2 / - \\
\hline $\begin{array}{l}\text { 8. Energia Eólica: por uma } \\
\text { revisão das bases } \\
\text { energéticas e incentivo a } \\
\text { economia de baixo carbono. }\end{array}$ & $\begin{array}{l}\text { Utilização do terreno, } \\
\text { interferências } \\
\text { eletromagnéticas, } \\
\text { acidentes com aves e } \\
\text { morcegos, sonoro, } \\
\text { visual e produção de } \\
\text { sombra e reflexo. }\end{array}$ & $\begin{array}{c}\text { Revista Eletrônica do } \\
\text { Curso de Direito da } \\
\text { UFSM / 1981-3694 }\end{array}$ & $\mathrm{A} 1 /$ - \\
\hline
\end{tabular}


Tabela 4. Artigos que tratam dos impactos ambientais ocasionados pela geração de energia eólica.

\begin{tabular}{|l|c|c|c|}
\hline Título do artigo & $\begin{array}{c}\text { Impacto ambientais } \\
\text { gerados }\end{array}$ & Revista/ISSN & $\begin{array}{c}\text { Qualis } \\
\text { /JCR/SJR }\end{array}$ \\
\hline $\begin{array}{l}\text { 9. Caminhos para uma } \\
\text { gestão participativa dos } \\
\text { recursos energéticos de } \\
\text { matriz renovável (parques } \\
\text { eólicos) no Nordeste do } \\
\text { Brasil }\end{array}$ & Territorial & $\begin{array}{c}\text { Mercator (Fortaleza) / } \\
1984-2201\end{array}$ & A1/- \\
\hline $\begin{array}{l}\text { 10. O mercado brasileiro de } \\
\text { energia eólica, impactos } \\
\text { sociais e ambientais }\end{array}$ & $\begin{array}{c}\text { Visual, sonoro, } \\
\text { interferências } \\
\text { eletromagnéticas e } \\
\text { acidentes com aves }\end{array}$ & $\begin{array}{c}\text { Revista Eletrônica } \\
\text { Ambiente \& Água / } \\
1980-993 X\end{array}$ & $\begin{array}{c}\text { A2/0,1720/ } \\
\text { Índice H 9 }\end{array}$ \\
\hline $\begin{array}{l}\text { 11. Sustentabilidade } \\
\text { municipal } \\
\text { empreendimentos eólicos: } \\
\text { uma análise comparativa de } \\
\text { municípios } \\
\text { investimentos na geração de } \\
\text { energia eólica no Brasil }\end{array}$ & & Revista Sociedade \& \\
Vatureza/1982-4513 & B1 \\
\hline
\end{tabular}

Entretanto, embora seja reconhecidamente uma forma de energia renovável de baixo índice de poluição, não se pode deixar de reconhecer que tanto a implantação dos parques eólicos como o seu funcionamento geram impactos negativos ao meio ambiente, pois como bem ponderou Loureiro et al. (2015) nenhuma forma de geração de energia é absolutamente limpa, sendo que certo grau de impacto ambiental é inevitável para qualquer que seja a fonte.

Como se observa da Tabela 4 os impactos ambientais ocasionados pela geração de energia eólica são de natureza sonora, visual, de restrição na utilização do solo e na utilização dos terrenos, de acidentes com aves e de radiação eletromagnética (Figura 2).

\section{Impactos abordados nos artigos}

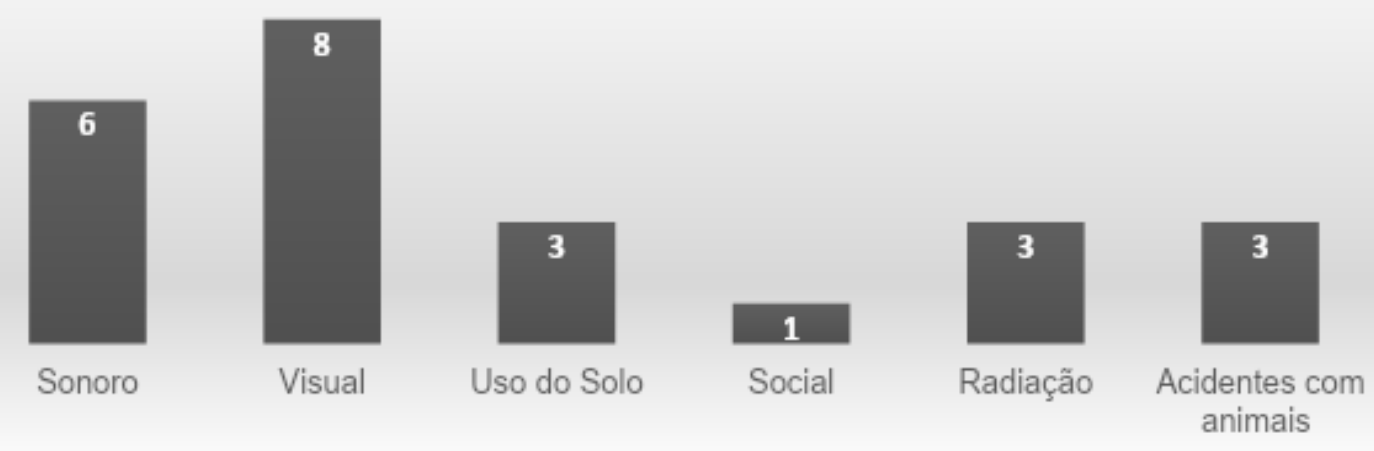

Figura 2. Impactos abordados nos artigos integrantes da revisão sistemática (Tabela 4). 
Alguns destes aspectos são altamente subjetivos, pois muitas pessoas olham para uma turbina eólica como um símbolo de energia limpa, enquanto outras reagem negativamente a paisagem, sendo difícil de mensurar certos impactos e principalmente, de criar alternativas para mitigá-los (Pinto et al, 2017).

Extrai-se dos excertos selecionados a etapa que se apresenta mais crítica quanto aos impactos ambientais gerados é a de construção, produzidos por uma planta de geração eólica, por ser o momento de maior alteração da paisagem previamente existente, devendo assim serem mitigados através de aplicação de novas tecnologias e planejamento adequado (Pinto et al, 2017).

Outras interferências e dificuldades analisadas referem-se à falta de capacitação das comunidades onde são implantados os geradores de energia eólica, a inexistência de legislação específica regulamentando a transmissão da energia gerada pelos empreendimentos, a burocracia para a liberação do licenciamento ambiental e para as construções dos parques eólicos, o desmatamento e a alteração da paisagem (Cândido et al., 2018).

Assim, considerando os vários aspectos e impactos ambientais citados nos artigos resultantes da revisão sistemática de literatura realizada neste estudo, na próxima seção eles serão discutidos e analisados pormenorizadamente.

\section{Discussão}

Conforme apresentado na coleta de dados, foram identificados 11 artigos acerca dos impactos ambientais ocasionados por meio da geração da energia eólica no Brasil, incluindo os fatores que podem acarretar os efeitos dessa atividade sobre o meio ambiente. Sendo que conforme apresentado na seção anterior, entre os principais impactos na implantação de um empreendimento eólico estão os sonoros, os visuais, a restrição do uso do solo, o impacto social causado, a radiação emitida e os acidentes com animais.

Parte dos artigos debruça-se a analisar estudos de casos específicos de implantação de parques eólicos, trazendo dados que permitem aferir materialmente os temas aqui tratados. Outros se restringem a análise retórica, mas ainda assim, complementando o debate acerca dos impactos negativos gerados pela energia eólica.

Os artigos foram publicados no período entre 2012 e 2018, apresentaram, além dos impactos ambientais, os aspectos relativos à expansão da geração da energia eólica no Brasil e suas características, como por exemplo, o caráter complementar a matriz hidroelétrica, os incentivos governamentais, aspectos normativos e regionais.

Para Nascimento et al. (2012), sob a perspectiva da sustentabilidade a energia eólica é uma das mais promissoras fontes de energia renovável, contudo gera impactos ambientais os quais são, barulho, invasão visual, acidentes com pássaros e radiação eletromagnética, sendo que são possíveis de evitar e inferiores aos ocasionados por outras fontes de energia. Para esses autores, os períodos com maior ocorrência de ventos no Brasil são compatíveis com as estações de menor capacidade produtiva de energia por meio das hidrelétricas, habilitando a energia eólica a ser o principal complemento do sistema preponderante no Brasil.

De acordo com Ribeiro et al. (2012), ao analisar uma usina eólica instalada no Piauí, sugerem a ocorrência de impactos positivos sob a perspectiva da gestão ambiental, educação e apoio a projetos sociais, em consonância com a política de sustentabilidade seguida pelos empreendedores. Por outro lado, os mesmos autores destacam que outras 
abordagens sobre $\mathrm{o}$ tema indicam impactos na fauna, ocasionando a inibição da reprodução de espécies em função do barulho gerado pela usina eólica.

Outros autores, ao analisarem a percepção dos moradores de uma comunidade no Ceará sobre os impactos ambientais da instalação e operação de uma usina eólica na comunidade, constataram diversos motivos de insatisfação, entre os quais, os entrevistados se sentiram impedidos de transitar pela praia, dunas e lagoas, bem como de executar atividades laborais e desfrutar do lazer no local (Moreira et al., 2013).

Loureiro et al. (2015) abordam o impacto da implantação de parques eólicos no Município de Aracaju, no litoral oeste do Ceará, e as possíveis perdas ambientais nos arredores das áreas destinadas aos geradores. Os autores afirmam que a instalação desse modal de produção de energia no local ocasionou impactos negativos como desmatamento do mangue, alterações nas morfologias de praias e desarticulação da dinâmica ambiental litorânea, em especial, nas áreas destinadas diretamente ao turismo, onde os geradores afetam a paisagem de forma mais significativa. De acordo com os autores, o estudo de impacto ambiental de considerar esses fatores, valendo-se de alternativas como instalação dos parques eólicos em locais alternativos, como "os tabuleiros pré-litorâneos, regiões mais elevadas, de maior estabilidade geomorfológica, localizadas à retaguarda dos campos dunares" (Loureiro et al., 2015, p. 24).

Em relação aos impactos sociais, Leite e Souza (2015), afirmam que há necessidade implementação de justiça ambiental, por meio de busca de condições que garantam a proteção dos grupos sociais envolvidos ou impactados pelos projetos, em especial, considerando que as zonas costeiras são, historicamente, habitadas por populações tradicionais e vulneráveis, como pescadores artesanais, indígenas, quilombolas, ribeirinhos, camponeses ou pequenos agricultores. Afirmam que essas populações estão mais expostas 'aos males ambientais embutidos nos projetos de desenvolvimento' e, por esse motivo, se faz necessária uma mudança nos processos decisórios, visando a efetiva participação dos grupos sociais atingidos pelos empreendimentos de fonte eólica, disseminando-se os "preceitos da equidade ambiental, garantindo-se, por conseguinte, a realização de justiça ambiental" (Leite e Souza, 2015, p. 249).

Segundo Gorayeb e Brannstrom (2016), a insegurança fundiária jurídica que afeta manutenção da permanência das populações tradicionais no território e a corrupção envolvendo o poder executivo local, fragilizam a preservação ambiental e os direitos dos cidadãos no litoral do estado do Ceará (Gorayeb e Brannstrom, 2016). Conforme os autores, foi possível observar manifestações contrárias à instalação de parques eólicos em 2012, 2014 e 2015, por meio de audiências públicas e abaixoassinados de organizações humanitárias, ambientais, associações de pescadores tradicionais, agricultores familiares e indígenas do litoral do Ceará (Gorayeb e Brannstrom, 2016).

Lima e Oliveira, 2015, abordam em seu artigo pela necessidade de incentivo, por parte do Estado, à energia eólica, por ser uma matriz energética de baixo impacto ambiental. Aduzem que a crise energética e as mudanças climáticas decorrentes da emissão de gases de efeito estufa são fortes fatores que influenciam a adoção de tal modal, em potencial, por ser uma fonte renovável capaz de substituir as fontes de combustíveis fósseis, além de criar postos de trabalho e aquecer o turismo local.

Campêlo e Albuquerque, 2016, constataram o impacto positivo sob os aspectos sociais, econômicos e ambientais da produção de energia eólica no Complexo Chapada do Piauí I, no 
Município de Marcolândia, Piauí. Foram instalados 115 geradores no Complexo, numa área destinada aos aerogeradores arrendada por vinte anos, com pagamentos mensais aos proprietários dos imóveis, gerando uma receita mensal direta à região de $\mathrm{R} \$ 1.000 .000,00$ (um milhão de reais) dos empresários aos donos das terras, que ainda são utilizadas para pecuária ou plantio de culturas como a mandioca (Campêlo e Albuquerque, 2016).

Segundo Gorayeb e Brannstrom (2016), durante a crise de energia elétrica do Brasil corrida em 2001, conhecida como o apagão, foi criada uma norma em regime especial, a Resolução n. 279 de 27 de julho (Brasil, 2001), substituindo uma resolução de 1997 que previa a elaboração de estudos de impacto ambiental e relatório de impacto ambiental (EIA/RIMA) (Brasil, 1997). Desta forma, para implantação de usinas eólicas, o empreendedor foi obrigado a apresentar apenas um relatório ambiental simplificado (RAS), acompanhado de declaração do técnico responsável informando o enquadramento do empreendimento como de pequeno potencial de impacto ambiental (Gorayeb e Brannstrom, 2016).

Ainda segundo Gorayeb e Brannstrom (2016), o RAS deveria incluir o diagnóstico ambiental da região do empreendimento, características e relação dos impactos ambientais e medidas de mitigação, controle e compensação. Contudo, no Ceará, estado no qual os autores realizaram o estudo, normalmente o documento é redigido precariamente por consultorias locais que geralmente replicam os dados de trabalhos anteriores comprometendo a qualidade e confiabilidade do relatório, por consequência ampliando a possibilidade de impactos negativos decorrentes da implantação dos parques eólicos (Gorayeb e Brannstrom, 2016).

Conforme Pinto et al. (2017), a fase crítica em relação aos impactos ambientais consiste na construção da planta de geração eólica. Além disso, segundo os autores, sob a perspectiva do impacto visual, a alteração na paisagem pode gerar desvalorização da região; o ruído aerodinâmico gerado pelas pás em atrito com o vento é de baixo impacto, por exemplo, menor do que em um ambiente de escritório; e a interferência eletromagnética em serviços de radiocomunicação móvel é frequentemente desprezível.

Outro aspecto abordado por Pinto et al. (2017), se refere a argumentação de que os aerogeradores podem causar o aumento da mortalidade de aves, contudo a ocorrência se relaciona principalmente com os primeiros empreendimentos, nos quais não ocorriam estudos prévios, a instalação dos parques eólicos, relativos às rotas de migração dos pássaros.

Os autores Oliveira et al. (2018), abordaram estudo relativo aos impactos sonoros na fase de instalação do empreendimento Parque Eólico Asa Branca II, no Município de Parazinho, Estado do Rio Grande do Norte. Os autores realizaram medição sonora com decibelímetro um mês antes do início das obras e ao longo dos 19 meses subsequentes, bem como, aplicaram questionário com a comunidade, para analisar como a fase de implantação do empreendimento afetou a qualidade sonora local. Segundo o estudo, em apenas um dos quatro pontos de medição, houve degradação sonora mínima $(4,5 \mathrm{~dB})$, em relação ao parâmetro tido anterior ao início das obras e sob a perspectiva da comunidade foi possível constatar que o empreendimento não afetou negativamente a qualidade sonora local (Oliveira et al., 2018).

Para Cândido et al. (2018), a sustentabilidade municipal em um conjunto de municípios que receberam a instalação de empreendimento eólicos na Paraíba foi afetada sob a perspectiva ambiental, em função das seguintes limitações, a ausência de fiscalização dos órgãos governamentais competentes, 0 
desmatamento e a alteração da paisagem local.

\section{Conclusão}

A ampliação da problematização em torno da geração de energia e os impactos ambientais, a modificação dos ecossistemas em razão dos gases de efeito estufa, bem como, da necessidade cada vez maior de fontes alternativas de energia, seja pelo aumento do consumo, seja em razão da utilização de matrizes energéticas finitas, como os combustíveis fósseis, potencializa os olhares sobre esse tema da energia eólica no Brasil.

O debate sobre os impactos é relativamente recente, coincidindo com a maximização do uso da energia eólica no Brasil.

Apesar de convergirem os artigos, no sentido de que a instalação de parques eólicos são capazes de causar impactos ambientais negativos, pode-se afirmar que, em sua maioria, os trabalhos integrantes desta revisão sistemática reconhecem que a energia eólica é uma fonte sustentável, renovável e com baixas externalidades, se comparada aos modelos convencionais não renováveis, como combustíveis fósseis, ou mesmo renováveis, como hidrelétricas, cujo impacto à vegetação, fauna, flora e recursos hídricos é significativamente maior nos arredores da represa (Oliveira et al., 2018).

No que se refere aos dispositivos de mitigação de impactos ambientais decorrentes da fonte eólica, os autores sugerem algumas alternativas. De acordo com Pinto et al. (2017), para mitigar o impacto do ruído aerodinâmico, os aerogeradores mais modernos tem sido alterado para emitir menos ruído, a interferência com serviços de radiocomunicação móvel e sinais de TV tem sido mitigada pela substituição das pás de metal por material sintético, quanto a colisão com aves, têm sido instalados estímulos visuais e sonoros nos aerogeradores para diminuir a ocorrência.
Entre as diversas propostas dos autores para compatibilizar a implantação dos parques de energia eólica no atendimento aos impactos atualmente subdimensionados, constam as seguintes: elaboração de normativos acerca da implantação da energia eólica a nível estadual e municipal, a partir da elaboração de leis e planos municipais; confecção de estudos de impacto ambiental que tenham como premissa a conscientização pública, a ampla informação e divulgação de estratégias de comunicação sobre os benefícios e possíveis danos ambientais e sociais; e elaboração de um zoneamento estadual identificando os níveis de compatibilidade das regiões do estado com a implantação de parques eólicos, com ampla participação social (Loureiro et al., 2015).

0 presente trabalho trouxe a reunião dos principais impactos ambientais associados a fonte de energia eólica no Brasil. Em que pese o trabalho ter abordado o enfoque ambiental, reunindo os principais impactos na implantação de um empreendimento eólico, os quais são, os sonoros, os visuais, a restrição do uso do solo, o impacto social causado, a radiação emitida e os acidentes com animais. Outros fatores relacionados às possíveis causas foram demonstradas por meio do estudo, a exemplo da simplificação relativa aos dispositivos de licenciamento ambiental, limitações na fiscalização dos órgãos governamentais e a necessidade constante de melhoria da tecnologia para mitigar os impactos.

A pesquisa em questão teve um enfoque no panorama da energia eólica sob a perspectiva dos impactos ambientais no Brasil. Diante do exposto, outros estudos podem ser abordados em futuras pesquisas acerca do tema, incluindo os seguintes: análise de percepção sobre a energia eólica das populações que são diretamente afetadas em seu território; abordagem sobre os aspectos socioeconômicos das populações locais subdimensionados 
durante a implantação dos empreendimentos eólicos; e a análise das possíveis consequências para os casos em que ocorre a substituição da elaboração de estudos de impacto ambiental e relatório de impacto ambiental (EIA/RIMA) pelo relatório ambiental simplificado (RAS) para implantação de empreendimentos eólicos.

Os resultados deste estudo podem contribuir com a possibilidade do aperfeiçoamento dos dispositivos mitigadores dos impactos ambientais gerados na produção deste tipo específico de energia renovável.

\section{Conflito de interesses}

Os autores declaram não haver conflito de interesses.

\section{Referências}

ABE Eólica - Associação Brasileira de Energia Eólica. Eólica já é a segunda fonte da matriz elétrica brasileira com $15 \mathrm{GW}$ de capacidade instalada. Disponível em: <http://www. portalabeeolica.org.br/>. Acesso em: 10 jun. 2019.

Alves, J. J. A. Análise regional da energia eólica no Brasil. Revista Brasileira de Gestão e Desenvolvimento Regional, v. 6, n. 1, p. 165-188, 2010.

Cândido, G. A. C. G.; Barbosa, A. P. A.; Brito, P. V. Sustentabilidade municipal e empreendimentos eólicos: uma análise comparativa de municípios com investimentos na geração de energia eólica no Brasil. Revista Sociedade \& Natureza, v. 30, n. 2, p. 68-95, 2018. https://doi.org/ 10.14393/SN-v30n2-2018-4

Campêlo, J. R.; Albuquerque, E. L. S. Energias renováveis e sustentabilidade: um olhar geográfico para o Parque Eólico de Marcolândia, Estado do Piauí, Brasil. Revista de Geociências do Nordeste, v. 2, p. 904912, 2016.
CAPES - Coordenação de Aperfeiçoamento de Pessoal de Nível Superior. Serviços: Banco de teses. 2019. Disponível em: <http://servicos.capes.gov.br/capesdw/>. Acesso em: 21 ago. 2019.

Damasceno, V. S.; Abreu, Y. V. Avaliação da energia eólica no Brasil utilizando a análise SWOT e PESTEL. Interações, v. 19, n. 3, p. 503-514, 2018 . https://doi.org/ 10.20435/inter.v19i3.1649

Duarte, C. G.; Dibo, A. P.; Sanchez, L. E. O que diz a pesquisa acadêmica sobre avaliação de impacto e licenciamento ambiental no Brasil? Ambiente \& Sociedade, v. 20, n. 1, p. 245-278, 2017. https://doi.org/10.1590/ 1809-4422asoc20150268r1v2012017

Fernandes, M. L. Proposta de um modelo de avaliação do desempenho da gestão de energia em Instituições de Ensino Superior (IES). Curitiba: Universidade Tecnológica Federal do Paraná, 2017. (Dissertação de mestrado).

Gil, A.C. Como elaborar projetos de pesquisa. 5. ed. São Paulo: Atlas, 2010.

Gorayeb, A.; Brannstrom, C. Caminhos para uma gestão participativa dos recursos energéticos de matriz renovável (parques eólicos) no nordeste do Brasil. Mercator,

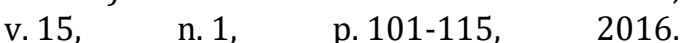
https://doi.org/10.4215/RM2016.1501.0008

Gorayeb, A.; Mendes, J, S.; Brannstrom, C.; Silva, E. Wind-energy development causes social impacts in coastal Ceará State, Brazil: The case of the Xavier Community. Journal of Coastal Research, v. 75, supl., p. 383-387,, 2016. https://doi.org/10.2112/SI75-077.1

Kitcher, P. Science in a democratic society. In: Kitcher, P. Scientific realism and democratic society. Leiden: Brill, 2011. (Serie Poznań Studies in the Philosophy of the Sciences and the Humanities Online, v. 101). p. 95-112. https://doi.org/10.1163/ 9789401207355_003

Kroehn, M. Como vento a favor: expansão na capacidade de geração, investimentos de fornecedores de equipamentos e redução de preço começam a tornar a energia eólica competitiva no Brasil. Exame, v. 45, n. 16, p. 72-73, 2011. 
Leite, D. B.; Souza, E. P. Tendências do cenário energético brasileiro: a energia de fonte eólica e o "olhar" dos atingidos. Ciência e Natura, v. 37, n. 3, p. 243-250, 2015. https://doi.org/10.5902/2179460X17322

Leusin, M. E.; Vaz, C. R.; Maldonado, M. U. Mapeamento tecnológico de patentes em energia eólica no Brasil. Future Studies Research Journal: Trends and Strategy, v. 10, n. 2, p. 303-329, 2018.

Lima, C. C.; Oliveira, M. L. Energia eólica: por uma revisão das bases energéticas e incentivo à economia de baixo carbono. Revista Eletrônica do Curso de Direito da UFSM, v. 10, n. 2, p. 619-645, 2015. https://doi.org/10.5902/1981369419748

Loureiro, C. V.; Gorayeb, A.; Brannstrom, C. Implantação de energia eólica e estimativa das perdas ambientais em um setor do litoral oeste do Ceará, Brasil. Geosaberes, v. 6, n. 1, p. 24-38, 2015.

Medeiros, S.; Aquino, F.; Barros, P.; Moura, L.; Araújo, A. Energia eólica: um estudo sobre a percepção ambiental no Município de Currais Novos/RN. Holos, v. 3, p. 83-103, 2009. https://doi.org/10.15628/holos.2009.248

Moreira, R. N.; Vidal, F. A. B.; Viana, A. F.; Oliveira, D. A. B. Energia eólica no quintal da nossa casa?! Percepção ambiental dos impactos sociambientais na instalação e operação de uma usina na Comunidade de Sítio do Cumbe em Aracati-CE. Revista de Gestão Ambiental e Sustentabilidade, v. 2, n. 1, p. 45-73, 2013.

Nascimento, T. C.; Mendonça, A. T. B. B.; Cunha, S. K. Inovação e sustentabilidade na produção de energia: o caso do sistema setorial de energia eólica no Brasil. Cadernos EBAPE.BR, v. 10, n. 3, p. 630-651, 2012.

Oliveira, V. M. M.; Maciel, A. B. C.; Reis, L. M. M. Poluição sonora: um estudo de caso do Parque Eólico Asa Branca II, localizado no Município de Parazinho-RN. Boletim de Geografia, v. 36, n. 1, p. 112-131, 2018. https://doi.org/10.4025/bolgeogr.v36i1.343 49

Pinto, L. I. C.; Martins, F. R.; Pereira, E. B. 0 mercado brasileiro da energia eólica, impactos sociais e ambientais. Revista Ambiente \& Água, v. 12, n. 6, p. 1082-1100, 2017. https://doi.org/10.4136/ambi-agua. 2064
Ribeiro, H. C. M.; Pierot, R. M.; Corrêa, R. Projeto de mecanismo de desenvolvimento limpo: um estudo de caso na Empresa de Energia Eólica do Estado do Piauí. Revista de Administração, Contabilidade e Sustentabilidade, v. 2, n. 2, p. 61-75, 2012. https://doi.org/10.18696/reunir.v2i2.61

Rodrigues, L. B.; Perobelli, F. F. C.; Vasconcelos, S. Geração de energia eólica no Brasil: um investimento viável? Revista Brasileira de Economia de Empresas, v. 17. n. 2, p. 71-94, 2017.

Silva, L. M.; Abreu-Harbich, L. V. Metodologia simplificada para avaliação do potencial de energia eólica em centros urbanos. PARC Pesquisa em Arquitetura e Construção, v. 8 , n. 1 , p. 46-58, 2017. https://doi.org/ 10.20396/parc.v8i1.8648501

Silva, V. P.; Pinheiro, J. Q. "Do que você lembra quando pensa em energia do vento?" Um estudo sobre o conhecimento da energia eólica. Revista Interamericana de Psicologia, v. 4, n. 2, p. 361-367, 2010.

Simas, M.; Pacca, S. Energia eólica, geração de empregos e desenvolvimento sustentável. Estudos Avançados, v. 27, n. 77, p. 99-116, 2013. https://doi.org/10.1590/S010340142013000100008

Soares, P. B.; Carneiro, T. C. J.; Calmon, J. L.; Castro, L. O. C. O. Análise bibliométrica da produção científica brasileira sobre Tecnologia de Construção e Edificações na base de dados Web of Science. Ambiente Construído, v. 16, n. 1, p. 175-185, 2016. https://doi.org/10.1590/s1678-86212016 000100067

Stefano, F. Estados que vivem de vento: um leilão de energia eólica em novembro deve impulsionar o setor, ainda insignificante no país, mas que tem tudo para atrair bilhões de reais e ajudar a desenvolver a economia do Nordeste. Exame, v. 43, n. 19, 2009.

Thimoteo, A. C. A.; Garcez, M.; Hourneaux, F. Jr. O uso e a importância dos indicadores de sustentabilidade nas organizações: estudos de casos em empresas de energia elétrica. Revista de Gestão Ambiental e Sustentabilidade, $\quad$ v. 4 , $\quad$ n. 13 , p. 89-102, $2015 . \quad$ https://doi.org/10.5585/geas. v4i3.325 
Vegara, S. C. Projetos e relatórios de pesquisa em Administração. 12. ed. São Paulo: Atlas, 2010.

\footnotetext{
(CC) Informação da Licença: Este é um artigo Open Access distribuído sob os termos da Licença Creative Commons Attribution, que permite uso irrestrito, distribuição e reprodução em qualquer meio, desde que a obra original seja devidamente citada.
} 